\title{
Remediation of Site Contamination
}

\author{
Ravi Naidu • Euan Smith • Ming H. Wong • Mallavarapu Megharaj • \\ Nanthi Bolan • Albert L. Juhasz • Enzo Lombi
}

Published online: 15 November 2013

(C) Springer Science+Business Media Dordrecht 2013

The effect of industrial contaminants on human health came to world scientific prominence in the 1950s when human exposure to mercury $(\mathrm{Hg})$ in Japan led to poisoning of thousands of local people (i.e. Minamata disease). Since that time, the effects of other contaminants such as arsenic, selenium, and asbestos has been reported in many countries. The race for economic growth in most countries

Guest Editors: R Naidu, Euan Smith, MH Wong, Megharaj Mallavarapu, Nanthi Bolan, Albert Juhasz, and Enzo Lombi

This article is part of the Topical Collection on Remediation of Site Contamination

R. Naidu $(\bowtie) \cdot$ E. Smith $\cdot$ M. Megharaj · N. Bolan •

A. L. Juhasz $\cdot$ E. Lombi

Centre for Environmental Risk Assessment and

Remediation, University of South Australia and CRC for

Contamination Assessment and Remediation of the

Environment (CRC CARE), Mawson Lakes Boulevard, SA

5095 Adelaide, Australia

e-mail: ravi.naidu@crccare.com

E. Smith

e-mail: euan.smith@unisa.edu.au

M. Megharaj

e-mail: megharaj.mallavarapu@unisa.edu.au

N. Bolan

e-mail: Nanthi.bolan@unisa.edu.au

A. L. Juhasz

e-mail: albert.juhasz@unisa.edu.au

E. Lombi

e-mail: enzo.lombi@unisa.edu.au

M. H. Wong

Croucher Institute for Environmental Sciences,

Hong Kong Baptist University, Hong Kong, Special

Administrative Region, People's Republic of China

e-mail: mhwong@hkbu.edu.hk has seen a dramatic increase in industrial activities which in turn has led to an exponential rise in the production of toxic wastes, many of which were disposed of into land and water bodies. These activities coupled with underground fuel storage tanks, mining, and military activities have resulted in millions of potentially contaminated sites worldwide (Table 1) which are largely located in densely populated areas.

At a conservative estimate, there are more than $5,000,000$ potentially contaminated sites worldwide. These represent both a lost economic opportunity and a real threat to the health and wellbeing of humans and the natural environment. With half of the population now living in cities, the demand for residential properties has forced local councils, planners, and regulators to consider new ways to manage contaminated sites. However, these sites represent a growing challenge given the nature of contaminants and the presence of complex chemical mixtures in most sites. These mixtures result in major differences in the fate and behaviour of the contaminants in both the soil and ground water environment and so, make remediation extremely challenging. Although site contamination was recognised some 60 years ago, efforts to remediate have been hampered by the complex and challenging nature of contamination, lack of regulatory policies enforcing polluters to remediate, or lack of adequate financial support.

\section{Knowledge Gaps}

There is a need for a change in the way we manage contaminated sites from both a regulatory as well as a remediation technology perspective. The former requires 
Table 1 The scale of environmental contamination challenge

\begin{tabular}{llll}
\hline Region & Number of contaminated sites & Value of current market & Reference \\
\hline Australia & 10,000 to 160,000 & Unknown & Johnston (2010) \\
Canada & 222,000 & Unknown & FCSAP (2005) \\
Germany & $\sim 360,000$ & Unknown & ICCS (2004) \\
USA & $\sim 350,000$ & $\sim$ \$US 250 billion & USEPA (2004) \\
\hline
\end{tabular}

sound evidence-based policies that lead to more realistic environmental and human health investigation levels. While much effort has been directed towards this, the process has mainly been driven by a few affluent countries. Many current remediation technologies were developed 30 years or more ago and are slowly being modified to suit contaminants being remediated; they need to be extensively updated to take account of the growth in complexity of contamination. Also, there is an urgent need to develop next generation green remediation technologies able to minimise greenhouse gas emissions. Furthermore, bio- and nano-technologies may offer a way forward, given the universal presence of microbes in soils, surface and ground water and the development of innovative high-reactivity nanomaterials able to tackle both organic and inorganic contaminants.

This special issue of WATE contains selected contributions from the CleanUp 2011 conference participants that highlight the current scientific and technical knowledge of contaminant site assessment and remediation. The papers in this special issue focus on:
(1) Fate and dynamics of contaminants;

(2) Potential risks associated with certain contaminants, and

(3) Soil and ground water remediation.

\section{References}

FCSAP. (2005). Federal contaminated sites action plan. Treasury Board of Canada Secretariat Website. http://www.tbs-sct.gc. ca/fcsi-rscf/home-accueil-eng.aspx. Accessed 25 Aug 2013.

ICCS. (2004). Management and remediation of contaminated sites: 30 years of German experience. International Centre for Soil and Contaminated Sites. http://germany-wuf.de/ upload/Management_Remediation.pdf. Accessed 25 Aug 2013.

Johnston, N. (2010). Unlocking the potential of brownfield sites. Remediation Australasia, 3, 20-25.

USEPA. (2004). Cleaning up the nation's waste sites: markets and technology trends. http://www.clu-in.org/download/ market/2004market.pdf. Accessed 25 Aug 2013. 